\title{
PERCEPÇÕES E PERSPECTIVAS DOCENTES SOBRE O ENSINO JURÍDICO EM UM INSTITUTO FEDERAL DE EDUCAÇÃO, CIÊNCIA E TECNOLOGIA
}

Kelly GIANEZINI ${ }^{1}$

RESUMO: O foco do trabalho é a expansão dos IFETs no Rio Grande do Sul e as perspectivas dos docentes que ministram as disciplinas de cunho jurídico em cursos superiores de graduação tecnológica. Analisou-se: o processo de expansão do ensino profissional e tecnológico no RS e as motivações que direcionaram os profissionais liberais da área jurídica para a docência e suas percepções profissionais neste campo. Foi necessário a utilização de dados quantitativos secundários disponibilizados por órgãos oficiais até o ano de 2010 e, também, adotou-se a metodologia qualitativa cuja coleta de dados foi efetuada mediante a realização de entrevistas semiestruturadas com questões abertas. Constatou-se a existência de alguns fatores que levaram os professores entrevistados a optar pela carreira docente na graduação tecnológica. Tais fatores incluem os anseios por estabilidade trabalhista comum a outras áreas; alternativas à saturação do mercado de trabalho jurídico; e a própria vocação para a docência.

PALAVRAS-CHAVE: Gestão educacional. Dilemas profissionais. Mercado de trabalho.

\section{Introdução}

O sistema que abrange a educação brasileira, principalmente a profissional e a tecnológica, se apresenta como um fenômeno plurifacetado resultante dos distintos tipos de instituições, das relações entre professores, alunos e quadro administrativo. Sobretudo, a nova configuração dos Institutos Federais de Educação, Ciência e Tecnologia (IFETs), resultante da política expansionista do governo federal. Em 2008, foram aproximadamente 18.000 novos alunos ingressantes nestas instituições e a relação entre matrículas e docência foi de 5,3 (INEP, 2008).

Dado o papel estratégico que a educação - mediante o ensino profissional e tecnológico (LDBN Lei no. 9.394/96 - expostos nos seus artigos 39 até 42) (BRASIL, 1996) - vem assumindo na qualificação profissional e na prestação de serviços, torna-se importante compreender as relações que estruturaram esse sistema educacional,

\footnotetext{
${ }^{1}$ Professora. Líder do Grupo de Estudo sobre Universidade. Membro do Núcleo de Estudos em Estado, Política e Direito. UNESC - Universidade do Extremo Sul Catarinense. Programa de Pós-Graduação em Desenvolvimento Socioeconômico. Criciúma - SC - Brasil. 88806-000 - kellygianezini@terra.com.br.
} 
promovendo sua expansão (GIANEZINI, 2009). Em especial, destacam-se a relação com a sociedade, o trabalho/formação de professores, as orientações institucionais, as perspectivas e os conflitos que dinamizam as instituições e sua expansão.

Em sintonia com a realidade local e inserida nas transformações do mundo do trabalho globalizado (SANTOS, 1996), optou-se neste artigo, pela análise do processo de expansão da educação profissional e tecnológica no estado do Rio Grande do Sul (RS), após a promulgação da Lei de Diretrizes e Bases da Educação Nacional (LDBN).

O foco do estudo está nas motivações que direcionaram os profissionais liberais da área jurídica para a docência e suas percepções profissionais neste campo, uma vez que as relações entre poder e conhecimento passam a ser mediatizadas por uma intensa profissionalização e institucionalização do saber (POPKEWITZ, 1997). Neste sentido a análise incidiu, especificamente, sobre a identidade, o papel e as funções dos professores das disciplinas jurídicas dos IFETs.

Considerando as novas exigências impostas pela sociedade contemporânea, por melhor qualificação de profissionais para o mercado de trabalho e, também, maior demanda na prestação de serviços, indaga-se: Quais são as características da identidade social destes novos docentes? Quais foram os fatores que influenciaram no (re)direcionamento do profissional liberal para o exercício da docência? Como o trabalho docente é visto por estes professores? A formação de professores poderia melhor instrumentalizar estes profissionais para o exercício da docência na educação profissional? Há alguma expectativa relacionada à educação continuada para estes professores?

Tais questões nortearam a pesquisa com intuito de compreender melhor a relação entre docência jurídica e mercado de trabalho no âmbito da temática estudada.

\section{Metodologia}

A investigação referente ao processo de expansão do ensino profissional e tecnológico no Rio Grande do Sul foi realizada a partir de um levantamento preliminar de dados disponibilizados por órgãos oficiais (MEC e INEP) que, juntamente com a análise documental e com a revisão bibliográfica, permitiram apresentar uma prévia do fenômeno da expansão.

Para analisar as motivações que direcionaram os profissionais liberais da área jurídica para o ensino profissional e tecnológico utilizou-se, qualitativamente, a técnica 
de entrevista semiestruturada, a fim de investigar os espaços de disputas entre os atores sociais para a sua manutenção no mercado de trabalho via docência. A coleta dos dados foi efetuada através da aplicação de um roteiro guia com questões abertas e analisadas pelo método de práticas discursivas, para entender os sentidos já que são “o meio e o fim de nossa tarefa de pesquisa" (SPINK, 1999, p.104).

Portanto, a finalidade da pesquisa consistiu no entendimento das motivações e das ideias-forças que deram sentido as ações dos atores sociais para a escolha da nova carreira, a docência.

Diante do enxuto quadro de docentes com a formação jurídica (Bacharelado em Direito ou em Ciências Sociais e Jurídicas) pertencentes ao IFET, a escolha pelos entrevistados foi dada aleatoriamente. ${ }^{2}$

\section{O cenário da expansão dos IFETs}

Após as décadas de 1980 e 1990 (nas quais o Brasil passou por um período longo de estagnação), o cenário econômico e produtivo se estabeleceu novamente, com o desenvolvimento de tecnologias complexas, agregadas tanto à produção quanto à prestação de serviços.

Em relação à educação, especialmente o sistema de educação superior no estado do Rio Grande do Sul, ocorreu várias transformações. Em 2004, havia 83 Instituições de Educação Superior (IES), das quais nove eram públicas e setenta e quatro eram privadas. No universo das IES públicas, oito eram federais e uma estadual. Das privadas, trinta e cinco eram particulares e trinta e nove comunitárias/confessionais/filantrópicas.

Quanto à organização acadêmica, até 2006 havia no estado 16 universidades, 6 centros universitários, 1 faculdade integrada, 52 faculdades, escolas e institutos superiores e 8 centros de educação tecnológica e faculdades de tecnologia (MOROSINI; ROSSATO, 2006).

Em seu estudo sobre a história da constituição das escolas, das universidades e da ciência nos Estados Unidos, Popkewitz (1997) demonstrou como a educação (básica

${ }^{2}$ O perfil dos entrevistados (faixa etária, sexo, estado civil, moradia, onde se graduou, ano de conclusão da graduação, vínculo empregatício, outras ocupações etc.) não é divulgado aqui devido à imediata identificação dos mesmos já que foi dada a garantia de confidencialidade. Contudo, o fato de ter focado em um IFET não invalida a intenção de proteger a identidade dos entrevistados, pois a instituição possui várias unidades (campi). 
e superior) se desenvolveu atrelada aos interesses políticos e econômicos. Embora o autor use os EUA como objeto de estudo, cabe trazer sua análise para a realidade dos IFETs no Brasil e no Rio Grande do Sul.

Desta forma é necessário, em primeiro lugar, compreender as transformações ocorridas na sociedade que influenciaram novas mudanças nas instituições técnicas federais de educação profissional na última década. Os diversos setores (industrial e comercial) passaram a exigir que seus trabalhadores se qualificassem tecnicamente. Coube, então, aos IFETs - e não as universidades - atender a esta demanda.

Historicamente, em âmbito nacional a rede federal de educação profissional, científica e tecnológica teve início em 1909, quando houve a criação de 19 escolas de Aprendizes e Artífices. A criação ocorreu na gestão do então presidente da república na época, Nilo Peçanha. Ao longo das décadas estes estabelecimentos de ensino receberam múltiplas nomenclaturas subsequentes, entre as quais: Escolas de Aprendizes e Artífices (EAA - 1909), Liceus Profissionais (LP - 1937), Escolas Industriais e Técnicas (EIT 1942), Escolas Técnicas (ET - 1959), Centros Federais de Educação Tecnológica (CFETs - 1978) e Institutos Federais de Educação Científica e Tecnológica (IFETs 2008). Tais alterações nominais visavam adequar o papel institucional que lhes competia à sua missão, sobretudo, em relação à sociedade brasileira.

No Brasil a rede federal de ensino técnico e tecnológico abrangia até 2008 quatro tipos de instituições: os Institutos Federais de Educação, Ciência e Tecnologia (IFETs); os Centros Federais de Educação Tecnológica (CFETS); as Escolas Técnicas (ET) vinculadas às universidades federais e a Universidade Tecnológica Federal (UTF) (INEP, 2008). No total são 34 instituições e no Rio Grande do Sul há três IFETs, todos multi-campi.

Este novo organograma institucional foi reorganizado - mediante os recentes arranjos institucionais - com o intuito de diversificar programas e cursos para elevar os níveis técnicos educacionais, colaborando, assim, com as exigências dos diversos setores da economia brasileira.

\section{O ensino jurídico nos IFETs}

Vinculados ao Ministério da Educação os IFETs oferecem distintos cursos em dois níveis de ensino, o nível médio que contempla a educação profissional técnica e o nível superior abrangendo a graduação e a pós-graduação (lato sensu e stricto sensu). 
Neste trabalho, especificamente, o enfoque analítico recaiu sobre as motivações dos responsáveis pelas disciplinas de cunho jurídico - professores do ensino profissional e técnológico que atuam no Instituto Federal do Rio Grande do Sul (IFET$\mathrm{RS}) .^{3}$

Cabe, aqui, lembrar que estes profissionais pertencem a uma seleta classe social de trabalhadores - os Bacharéis em Direito - que por muitas décadas foram considerados como a elite econômica e intelectual brasileira (OLIVEN, 1990; ADORNO, 1988).

Ao questionar os professores sobre a opção feita, o segundo entrevistado manifestou sua perspectiva: "eu vejo o trabalho docente como momentâneo na minha vida. Ainda tenho esperança de passar em um concurso para a magistratura [juiz]" (P2). Para auxiliar a compreensão sobre esta perspectiva destaca-se o que Hargreaves (2004, p. 26) afirma sobre a nossa sociedade, especialmente "[...] a sociedade do conhecimento tem dificuldade de fazer do ensino uma verdadeira profissão de aprendizagem".

A estabilidade é uma forte influência no (re)direcionamento do profissional liberal para o exercício da docência, como relata o terceiro entrevistado: "eu tenho $O A B$ e tudo mais... mas, depois de cinco anos advogando eu percebi que não era bem o que eu queria. A estabilidade foi uma coisa que me atraiu e depois acabei gostando de ensinar" (P3).

Salienta-se, novamente, que os professores ministrantes das aulas de legislação nos IFETs possuem Bacharelado em Direito, portanto não possuem formação na área das licenciaturas. Nesse sentido Colaço (2006, p.13), salienta que "historicamente, é possível evidenciar o quanto a formação didática docente universitária foi negligenciada no Brasil de uma forma geral, exceto nos cursos de licenciatura e pedagogia”.

Quando indagou-se sobre as possíveis expectativas em buscar conhecimento didático pós ingresso no IFET, o primeiro entrevistado destacou: "eu sabia que não tinha licenciatura [em Direito] então, depois do bacharelado eu fui fazer curso de

\footnotetext{
${ }^{3}$ Em relação a sua trajetória transformadora e expansiva a instituição surgiu a partir da integração de antigas instituições que foram transformadas, respectivamente, em Campus Bento Gonçalves, Campus Canoas, Campus Porto Alegre, Campus Rio Grande e Campus Sertão: Centro Federal de Educação Tecnológica de Bento Gonçalves; Escola Técnica Federal de Canoas (em implantação); Escola Técnica, até então vinculada à UFRGS; Colégio Técnico Industrial Prof. Mário Alquati, de Rio Grande; Escola Agrotécnica Federal de Sertão. O Campus Erechim iniciou as atividades letivas em 2009 e outros três campi estão em fase de implantação: Caxias do Sul, Osório e Restinga. Também compõem a estrutura do IFET - RS as unidades que foram federalizadas nas seguintes cidades: Farroupilha, Feliz e Ibirubá.
} 
extensão em metodologia de ensino e didática" (P1). ${ }^{4}$ Para Colaço (2006, p.26) "o maior desafio é vencer a resistência, a falta de motivação, o pouco interesse e a incompreensão da importância do conhecimento da pedagogia pelos professores profissionais e pelos profissionais do Direito".

Sobre os desafios em sala de aula e a relação entre professores e alunos o segundo entrevistado relatou: "é difícil dar aula para eles... porque a gente sabe que não estamos formando Bacharéis em Direito e sim tecnólogos em outras áreas o que para mim é um grande problema. Talvez falte uma metodologia ou dinâmica para identificar onde estamos acertando e errando" (P2).

Neste momento, convém esclarecer que no IFET-RS existem doze cursos no ensino médio oferecidos na modalidade subsequente ou PROEJA, uma licenciatura com habilitação em biologia e química e três cursos superiores de tecnologia. As principais disciplinas de cunho jurídico são: Direito I e II, Direito Empresarial, Direito Trabalhista, Direito Trabalhista Aplicado, Direito Tributário Aplicado, Direito do Trabalho Previdenciário, Direito Ambiental e Legislação Ambiental.

Ao retornar ao questionamento do entrevistado (P2) sobre onde se está errando, destaca-se o pensamento de Giles (2004, p.141), em seu artigo "A escola da sociedade do conhecimento: uma entidade em extinção" no qual salientou vários procedimentos que podem auxiliar os novos professores. Um deles é a realização de "coleta de avaliações e outros dados para investigar e avaliar os avanços e os problemas do decorrer do tempo".

Paralelamente, Hargreaves (2004, p.44), aponta que em um mundo em transformação, com a expansão do conhecimento, significativas mudanças nas comunidades e políticas educacionais descontínuas,

[...] os professores da sociedade do conhecimento devem desenvolver e ser ajudados a desenvolver as capacidades de correr riscos, lidar com a mudança e desenvolver investigações quando novas demandas e problemas diferentes os confrontarem repetidamente. É necessário criatividade.

Com relação à perspectiva de aprendizagem (didática) docente o terceiro entrevistado comentou: "acredito que deveria haver uma preparação para a docência neste nível de ensino. O IFET até tem uma política capacitação, mas acho que precisa

\footnotetext{
4 A letra "P" significa professor e o número posterior a esta letra $(1,2,3)$ representa a ordem em que foram realizadas as entrevistas. Tais entrevistas foram realizadas ao longo de 2010.
} 
melhorar" (P3). Aqui, ressaltam-se as lacunas da formação de Bacharelado em Direito. A falta de um estágio aliado as disciplinas voltadas para o magistério torna-se evidente. Para ilustrar destaca-se abaixo um excerto do Parecer CNE/CP 21/2001 que trata do estágio nas licenciaturas.

Estágio é o tempo de aprendizagem que, através de um período de permanência, alguém demora em algum lugar para aprender a prática de um ofício para depois poder exercê-lo. Assim, o estágio supõe uma relação pedagógica entre alguém que já é profissional reconhecido em um ambiente institucional de trabalho e um aluno estagiário. (BRASIL, 2001).

Neste sentido é apropriado lembrar o questionamento de Bordas (2005, p.88) sobre o ato de "ensinar na universidade seria uma ocupação ou seria uma profissão?" Embora esta interrogação tenha sido feita em relação ao desempenho de docentes de bacharelado, tal pergunta é pertinente ao contexto deste trabalho uma vez que os dilemas tanto na graduação tecnológica quanto no bacharelado e na licenciatura parecem ser pertinentes aos desafios da educação superior brasileira. Afinal, tratando-se do papel dos professores do ensino profissional e tecnológico, os professores que possuem o diploma em Bacharel em Direito não tiveram em sua formação o estágio supracitado.

\section{Considerações finais}

Com a realização deste estudo, preliminarmente, observou-se que o fenômeno da expansão dos IFETs caracterizou-se como uma (re)organização de novas instituições, alterando o número de unidades (campi) e o acesso mediante a expansão de matrículas.

Quanto ao ensino jurídico nestas unidades constatou-se a existência de alguns fatores que levaram os professores entrevistados a optar pela carreira docente nos cursos superiores de graduação tecnológica. Tais fatores incluem os anseios por estabilidade trabalhista, comum a outras áreas, alternativas à saturação do mercado de trabalho jurídico (advocacia) e a própria vocação para a docência. 


\section{FACULTY PERCEPTIONS AND PERSPECTIVES ON LEGAL EDUCATION IN A BRAZILIAN FEDERAL INSTITUTE OF EDUCATION, SCIENCE AND TECHNOLOGY}

ABSTRACT: This study focuses on the expansion of Federal Institutes of Education Science and Technology (IFETs) in Rio Grande do Sul state (Brazil) and the perspectives of professors who teach law disciplines in undergraduate courses. We analyzed: the process of expansion of technological education in Rio Grande do Sul state and the motivations that guided the lawyers for teaching and their perceptions and professional perspectives in this field. We use official quantitative data available and a qualitative methodology in which data collection was performed by conducting semistructured interviews. It was found that there are some factors that led the professors (faculty) interviewed to opt for teaching career in undergraduate programs. Such factors include the desire for job stability common to other areas, alternatives to saturation of lawyer's labor market, and vocation for teaching.

KEYWORDS: Educational management. Professional dilemmas. Labor market.

\section{REFERÊNCIAS}

ADORNO, S. Os Aprendizes do Poder: O Bacharelismo Liberal Na Política Brasileira. Rio de Janeiro: Paz e Terra, 1988.

BORDAS, M. C. Formação de professores no ensino superior: aprendizes da experiência. In: REUNIẪO ANUAL DA ANPED, 28., Caxambú, MG. Anais... Caxambú, MG, 2005.

BRASIL. Lei no 9.394, de 20 de dezembro de 1996. Fixa as diretrizes e bases da educação nacional. Diário Oficial, Brasília, 1996. v.134, n.248.

BRASIL. Conselho Nacional de Educação. Parecer CNE/CP 21/2001. 2001. Disponível em: <http://portal.mec.gov.br/dmdocuments/cnecp_212001.pdf〉. Acesso em: 15 jan. 2015.

COLAÇO, T. L. Ensino do direito e capacitação docente. In: COLAÇO, T. L. (Org.). Aprendendo a ensinar direito o direito. Florianópolis: OAB-SC, 2006. p.59-81.

GIANEZINI, Q. O processo de expansão do ensino superior em Mato Grosso. 2009. 250 p. Dissertação (Mestrado em Sociologia) - Programa de Pós-Graduação em Sociologia, Universidade Federal do Rio Grande do Sul, 2009.

GILES, C. A escola da sociedade do conhecimento: uma entidade em extinção. In: HARGREAVES, A. O ensino na sociedade do conhecimento: educação na era da insegurança. Porto Alegre: Artmed, 2004. p.73-97.

HARGREAVES, A. O ensino na sociedade do conhecimento: educação na era da insegurança. Porto Alegre: Artmed, 2004. 
INSTITUTO NACIONAL DE ESTUDOS E PESQUISAS ANÍSIO TEIXEIRA. Censo da Educação Superior. 2008. Resumo Técnico. Brasília: MEC/INEP, 2008.

MOROSINI, M.; ROSSATO, R. Educação superior no Rio Grande do Sul: 1991 2004. In: INSTITUTO NACIONAL DE ESTUDOS E PESQUISAS EDUCACIONAIS ANÍSIO TEIXEIRA [INEP]. A Educação Superior Brasileira: 1991 - 2004. Rio Grande do Sul; Brasília: INEP, 2006. p.55-76.

OLIVEN, A. C. A paroquialização do ensino superior. Petrópolis: Vozes, 1990.

POPKEWITZ, T. S. Reforma educacional: uma política sociológica poder e conhecimento em educação. Trad. Beatriz Afonso Neves. Porto Alegre: Artes Médicas, 1997.

SANTOS, B. de S. Pela mão de Alice: o social e o político na pós-modernidade. 2.ed. São Paulo: Cortez, 1996.

SPINK, M. J. Rigor e visibilidade: a explicitação dos passos da interpretação. In: SPINK, M. J. (Org.). Práticas discursivas e produção dos sentidos cotidianos: aproximações teórico metodológicas. São Paulo: Cortez, 1999. p.12-31. 